\title{
Perspective
}

PERSPECTIVE Actualité en histoire de l'art

Comptes rendus | 2009

\section{Michael Camille, The Gargoyles of Notre-Dame: Medievalism and the Monsters of Modernity, Chicago, University of Chicago Press, 2009}

\section{Pierre-Yves Le Pogam}

\section{(2) OpenEdition \\ Journals}

Édition électronique

URL : http://journals.openedition.org/perspective/2821

DOI : $10.4000 /$ perspective. 2821

ISSN : 2269-7721

Éditeur

Institut national d'histoire de l'art

Référence électronique

Pierre-Yves Le Pogam, « Michael Camille, The Gargoyles of Notre-Dame: Medievalism and the Monsters of Modernity, Chicago, University of Chicago Press, 2009 », Perspective [En ligne], Comptes rendus, mis en ligne le 05 août 2013, consulté le 01 octobre 2020. URL : http://journals.openedition.org/perspective/ 2821 ; DOI : https://doi.org/10.4000/perspective.2821

Ce document a été généré automatiquement le 1 octobre 2020. 
Michael Camille, The Gargoyles of Notre-Dame: Medievalism and the Monsters of Modernity, Chicago, University of Chicago Press, 2009

Pierre-Yves Le Pogam

\section{RÉFÉRENCE}

Michael Camille, The Gargoyles of Notre-Dame: Medievalism and the Monsters of Modernity,

Chicago, University of Chicago Press, 2009. 
Il s'agit du dernier livre de Michael Camille, paru à titre posthume (et malgré cette difficulté, l'ouvrage est d'une très grande qualité éditoriale, seules quelques notes bibliographiques étant restées inachevées). Il faut rendre hommage à la fois aux amis et collègues de Camille d'avoir permis la publication d'un livre important et surtout à l'auteur lui-même qui, après sa disparition, nous livre encore un nouvel exemple de ses réflexions si stimulantes pour les médiévistes. Ici, Camille aborde la question des "gargouilles» et plus globalement des

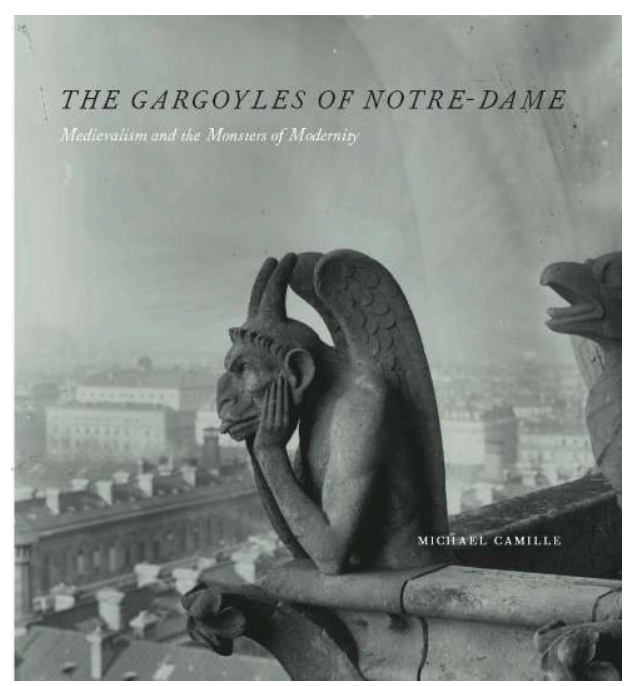
statues qui ornent les parties hautes de la façade de Notre-Dame de Paris, dont la fameuse "stryge ». Comme chacun sait, il s'agit de sculptures entièrement dues à la restauration $\mathrm{du} \mathrm{XIX}^{\mathrm{e}}$ siècle; pourtant, il s'agit d'œuvres fondamentales pour les historiens de l'art médiéval, d'une part parce qu'elles concentrent toutes les qualités et les travers induits par le regard porté par le XIX ${ }^{\mathrm{e}}$ siècle sur le Moyen Âge, et d'autre part parce qu'elles représentent paradoxalement, pour une immense majorité du grand public, la quintessence même de l'art médiéval! Dans cette étude très fouillée, Camille traite donc à la fois les processus de création de ces œuvres néomédiévales, les ressorts idéologiques de leur configuration et de leur iconographie, et enfin leur immense fortune critique (ou "acritique »!) dans la littérature, la photographie, le cinéma, en bref dans les arts et la pensée de la fin $d u X x^{e}$ et $d u x^{e}$ siècle. On pourra peut-être trouver telle ou telle thèse un peu excessive ou caricaturale; néanmoins, Camille a eu le mérite d'aborder de front cet objet d'étude difficile (y compris à cause de l'état de dégradation de l'ensemble depuis un siècle et donc de sa quasi recréation subséquente) et d'en rendre compte de manière à la fois subtile et globalement convaincante. 